\title{
Design and Comprehension Testing of Tailored Asthma Control Infographics for Adults with Persistent Asthma
}

\author{
Adriana Arcia ${ }^{1} \quad$ Maureen George $^{1} \quad$ Maichou Lor $^{1} \quad$ Sabrina Mangal ${ }^{1} \quad$ Jean-Marie Bruzzese ${ }^{1}$ \\ ${ }^{1}$ Columbia University School of Nursing, New York, New York, \\ United States \\ Address for correspondence Adriana Arcia, PhD, RN, Columbia \\ University School of Nursing, 560 West 168th Street, MC 6, New York, \\ NY 10032, United States (e-mail: adrianaxarcia@gmail.com).
}

Appl Clin Inform 2019;10:643-654.

\begin{abstract}
Background Adherence to daily inhaled corticosteroid medication is important for asthma control but low health literacy is a barrier to comprehension of control status and may contribute to medication nonadherence. Infographics tailored with patients' own data can support comprehension of health status, but these have not been applied to asthma successfully.

Objectives This two-phased study developed and tested tailored infographics of (1) scores on the Asthma Control Questionnaire (ACQ), a self-report measure of symptom burden, and (2) pulmonary function test (PFT) results. The infographics are intended for use as communication and adherence-promotion tools in clinical interactions.

Methods For both phases, participants (18+ years, English- or Spanish-speaking, persistent asthma) were recruited through two primary care clinics. In Phase I, we used a hybrid iterative participatory design process to refine prototype designs. In Phase II, we conducted individual comprehension assessment interviews with the finalized designs. Infographics were hand-tailored for each participant using their ACQ score and PFT results collected at the start of the interview. Two independent raters scored interview transcripts for gist and verbatim comprehension based on a predetermined rubric.

Results The five Phase I design sessions led to final prototypes that participants $(n=21)$

Keywords

- comprehension

- visual aids

- patient

- consumer health

- medication adherence

- language/health literacy issues considered appealing and easy to comprehend. All Phase II participants $(n=10)$ demonstrated complete gist and verbatim comprehension. Participants reacted favorably to receiving their information via infographics and expressed intentions to engage in selfmanagement behaviors (e.g., medication adherence, smoking cessation, weight loss, and review of their care plan) in response to the information.

Conclusion This study provides preliminary evidence that infographics can support comprehension of asthma control status and promote self-management intentions among adults with persistent asthma. Infographics can be programmed into electronic health records and/or standalone applications to allow for instant tailoring at the point of care.
\end{abstract}

\section{Background and Significance}

Adherence to daily inhaled corticosteroid (ICS) medication is important for asthma control; nearly every death or hospitalization due to asthma could be prevented with appropriate ICS use. ${ }^{1}$ However, uncontrolled asthma due to poor ICS adherence is common, ${ }^{2}$ particularly among ethnic and racial minority adults. ${ }^{3}$ Minority adults are also disproportionately represented among those with low health literacy, reflecting lower educational attainment and limited English proficiency among nonnative English speakers. ${ }^{4}$ Low health literacy is received

April 15, 2019

accepted after revision

June 17, 2019 (c) 2019 Georg Thieme Verlag KG Stuttgart · New York
DOI https://doi.org/

$10.1055 / \mathrm{s}-0039-1693713$. ISSN 1869-0327. 
a barrier to comprehension of asthma control status and may contribute to medication nonadherence. ${ }^{5-11}$ Prior adherence promotion efforts have focused on communicating proper inhaler technique, but have not highlighted the rationale behind improved adherence, namely poor asthma control. ${ }^{12}$ Therefore, supporting comprehension of asthma control status may be a useful approach to promoting adherence, thereby addressing one of the primary drivers of disparities in asthma outcomes. ${ }^{3}$

Recent studies have examined the use of information visualization for supporting comprehension of health data. The assumption underlying these studies is that leveraging people's existing visual analysis skills minimizes cognitive load, thereby easing the acquisition of new information. ${ }^{13}$ The theoretical premise of our study is that, as per the Health Belief Model, ${ }^{14}$ exposure to health information (i.e., a visualization) will alert the viewer to their susceptibility to a health threat and thus function as a cue to taking preventive health action.

Various information visualization formats have been studied for specific uses. A reference range number line (RRNL) is an information visualization format in which a clinical value can be visually compared with one or more relevant criterion rages. These have been described variously in the literature as block/gradient lines, ${ }^{15}$ progress bars, ${ }^{16}$ and bar graphs, ${ }^{17}$ to cite a few; we propose that the term RRNL is preferable because it is both accurate and descriptive. RRNLs are demonstrably superior to tabular and other graphical formats for displaying laboratory values such as cholesterol, ${ }^{17}$ hemoglobin A1c, ${ }^{15,18,19}$ and fasting blood glucose, ${ }^{20}$ as well as for clinical values such as blood pressure and body mass index. ${ }^{17,21}$ Icon arrays comparing the risks associated with various treatment conditions have been shown to narrow the comprehension gap for people with low health literacy. ${ }^{22-24}$ Pictograms and illustrations are sometimes useful for conveying medication administration instructions, ${ }^{25-28}$ but success depends heavily upon the cultural appropriateness of the images; testing with end users is critical for evaluating comprehensibility. ${ }^{29}$ Similarly, infographics that incorporate icons have been tailored with research participants' data to successfully support comprehension of health status, but members of the target audience must be part of the design process to ensure the cultural relevance of the icons selected. ${ }^{21,30}$ Advances in informatics now permit easy conversion of patient/participant data into finished, tailored infographics. ${ }^{31}$

A variety of patient-facing visualizations for asthma are documented in the literature. These include illustrated asthma action plans, ${ }^{32-36}$ inhaler instructions with pictograms and/or illustrations, ${ }^{37,38}$ measurement instruments with illustrated response options, ${ }^{39,40}$ graphical patient-reported outcome summaries, ${ }^{41}$ and interfaces for mobile apps that track symptoms over time. ${ }^{42-44}$ The use of stoplight colors (green, yellow/ orange, and red) are common across these visualizations, as are images of inhalers, suns and moons (to represent medication dosing times), and people having difficulty breathing. Of the aforementioned patient-facing visualizations, only the graphical patient-reported outcome summaries are intended to show cross-sectional data about asthma control status. Specifically, Turner-Bowker et $\mathrm{al}^{41}$ used a simple number line to display scores for the Asthma Control Test (ACT) ${ }^{45}$ alongside scores for other patient-reported outcome measures. Some participants found the graphical output confusing, possibly owing to the presentation of multiple metrics on one page, or because the number lines had only text anchors to support score interpretations. ${ }^{41}$ As such, there is a gap in the literature with regard to optimal formats for supporting comprehension of asthma control status.

\section{Objectives}

The objective of this two-phased study was to develop and test English- and Spanish-language tailored infographics of (1) scores on the Asthma Control Questionnaire (ACQ), ${ }^{46}$ a self-report measure of symptom burden, and (2) pulmonary function test (PFT) results. The infographics are intended for use as communication and adherence-promotion tools in clinical interactions.

\section{Methods}

\section{Participants}

For both phases, participants were recruited through a federally qualified health center in Philadelphia and a primary care clinic in New York City, both of which serves a predominantly low-income, racial/ethnic minority population. To be eligible to participate, patients had to be 18 years or older, able to see and read large print text in English or Spanish (by self-report), and have persistent asthma, defined as having been prescribed a daily ICS. Eligible patients were notified of the study by mail and had the opportunity to opt out of recruitment. Those who did not opt out were contacted by phone using an institutional review board-approved telephone script. Each participant attended only one design session or interview; Phase I participants were ineligible for Phase II. Written informed consent was obtained from all participants.

\section{Measures}

We measured asthma control status with ACQ (used with permission). ${ }^{46}$ Scores are averaged across six symptombased self-report items to yield a total score ranging from 0.00 to 6.00 ; scores 1.50 and greater indicate uncontrolled asthma in clinical trials. A change of 0.5 units is considered clinically meaningful. ${ }^{46}$

We performed PFT (Phase II only) using an EasyOne Air portable spirometer (ndd Medical Technologies, Inc.) to record forced expiratory volume in one second $\left(\mathrm{FEV}_{1}\right)$, the reference value for a nonsmoker without asthma of comparable age, sex, height, and race/ethnicity ( $\mathrm{FEV}_{1}$ predicted), and the percentage of unobstructed lung volume $\left(\mathrm{FEV}_{1} \%\right.$ predicted). The latter is classified as mild ( $80 \%$ or more), moderate (60-79\%), or severe (59\% or less) asthma. ${ }^{1}$

To assess health literacy, we used the Newest Vital Sign $(\mathrm{NVS})^{47}$ which is based on the number of correct responses to questions about information shown on a nutrition label. Scores of 0 and 1 suggest a high likelihood of limited literacy, 
scores of 2 to 3 indicate the possibility of limited literacy, and scores of 4 to 6 indicate adequate literacy.

\section{Phase I, Iterative Participatory Design Sessions}

We used a hybrid iterative participatory design process ${ }^{21}$ in which the initial prototype infographic designs were developed by experts (the lead investigators, A.A. and M.G., and a graphic designer) and then iteratively refined with feedback from members of the target audience (i.e., adults with persistent asthma) in group participatory design sessions. The goal was to refine one or more successful designs for each of the two topics, ACQ score and PFT results. A design was considered successful when the participants indicated that it was appealing and when their interpretations of its meaning matched the meaning we intended.

In preparation for the first session, the research team prepared multiple prototype designs for each topic (see - Figs. 1 and 2 for examples) in both English and Spanish. These designs were informed by an earlier exploratory study. ${ }^{48}$ Text was translated into Spanish by two bilingual members of the research team.

Phase I sessions took place at the clinics from which participants were recruited. We collected ACQ scores and demographic data and administered the NVS. The designs were tailored with the simulated data of fictitious characters and printed on U.S. Letter size card stock. Each participant was given his or her own stack of designs, and these were reviewed one at a time as a group. Facilitators experienced in participatory design elicited participants' interpretations of meaning by asking "What information do you think we are trying to convey with this image?" After reviewing the various designs for a topic, we asked participants to select their preferred design by voice or hand vote. Discussion focused on the reasons for participants' preferences and their suggestions for improvement. To assess for self-management motivation, we asked, "Would this image motivate you to address the health issue?" Sessions, which each lasted about 2 hours, were audio-recorded; assistants took notes. Participants were each compensated $\$ 50$ for their time.

The goal of data analysis was to identify the design elements that contributed to or hindered comprehension. Therefore, analysis was concurrent with data collection such that design sessions were followed by a peer debriefing for the members of the research team to review notes, discuss and synthesize impressions, and come to consensus about next steps. The principal investigator and graphic designer performed design iterations between sessions, refining promising designs and discontinuing unsuccessful ones, as per research team consensus. They maintained detailed notes about design decisions and

\section{Victor's Level of Asthma Control}

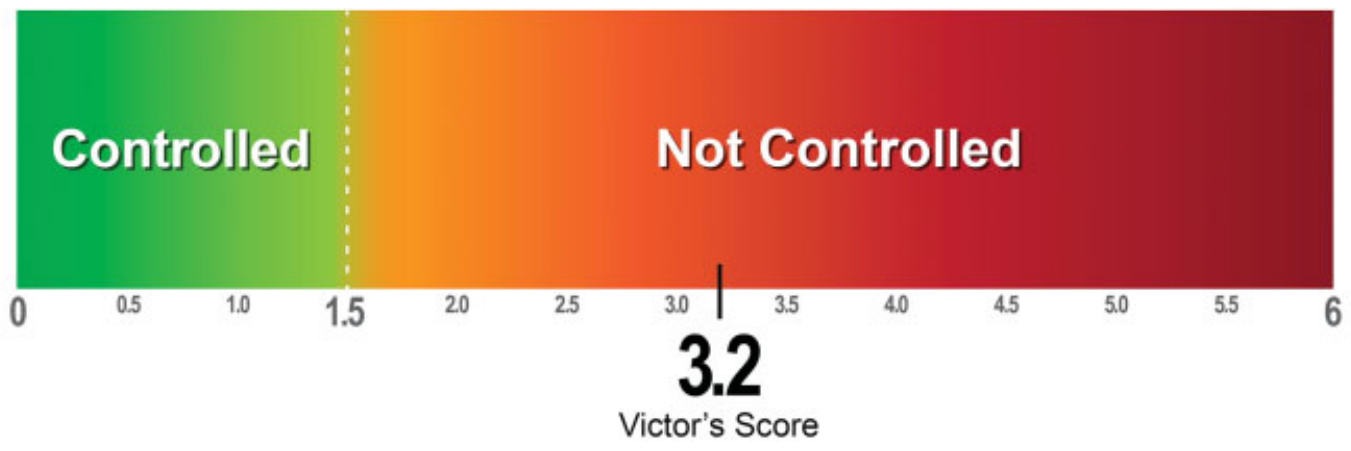

Visit on: January 2, 2018 Seen by: J. Cardozo, FNP

Fig. 1 Initial prototype design of the Asthma Control Questionnaire (ACQ) infographic. CC BY 4.0 Adriana Arcia \& Nicole Spiegel-Gotsch for Columbia Nursing, https://doi.org/10.7916/d8-w8hz-w605, p. 8. 


\section{What do the results of my lung function test mean?}

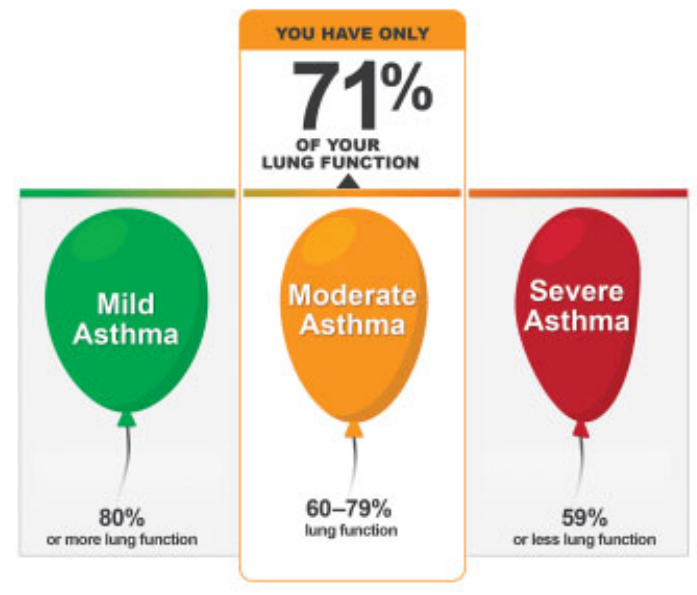

Understanding Your Numbers

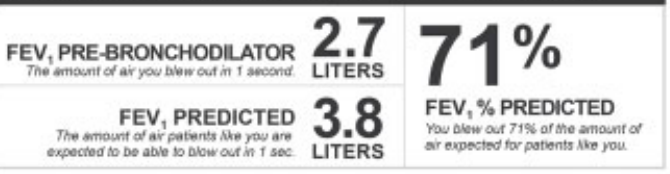

Fig. 2 One of the initial prototype designs of the pulmonary function test (PFT) infographic that proved unsuccessful. CC BY 4.0 Adriana Arcia \& Nicole Spiegel-Gotsch for Columbia Nursing, https://doi.org/ 10.7916/d8-w8hz-w605, p. 21.

the rationale for them that, alongside the notes and transcripts, later functioned as an audit trail. Sessions continued until reaching design saturation which is the point at which participants express satisfaction with the remaining designs and do not identify the need for further substantive changes.

\section{Qualitative Rigor}

We promoted qualitative rigor through the use of confirmatory audit trails methods (e.g., triangulation between research team members and peer debriefing) as well as the use of a dependability audit (e.g., showing designs in multiple sessions before making a final decision to discontinue a design or consider it successful).

\section{Phase II, Individual Comprehension Assessment Interviews}

Participants were scheduled for individual hour-long interviews and received $\$ 25$ for their time. Interviews took place either at the clinic from which participants were recruited (in Philadelphia) or at Columbia University School of Nursing in New York City. We collected demographic data and administered the NVS then asked, "We are going to determine whether or not your asthma is controlled based on some questions about your symptoms. Do you expect your asthma to be controlled or not controlled? Your best guess is fine." and "We are also going to do a test of your lung function. It will tell us if your asthma is mild, moderate, or severe. What do you expect the result to be? Your best guess is fine." We asked these questions to later evaluate if the unexpectedness of a result might hinder comprehension, as has been found in previous work. ${ }^{49}$ Participants then completed the ACQ and we performed PFTs.

The principal investigator (A.A.) hand-tailored infographics with the participant's ACQ score and PFT results. The infographics were printed on U.S. Letter size card stock and folded into pamphlets. For the ACQ infographic, we used the design shown in -Fig. 3 except that we displayed only one score and interpretive statement; the PFT infographic design was unchanged from the one shown in -Fig. 4. For both infographics, we omitted the care plan summary on the back cover because we did not have the participant's clinician on hand to provide specific recommendations.

The principal investigator assessed comprehension using the International Organization for Standardization (ISO) 9186 method for testing comprehensibility of symbols, ${ }^{50}$ modified for verbal administration. ${ }^{51}$ The investigator first showed a "No Smoking Within 25 Feet" symbol and delivered the following script:

Let's say I show this sign to someone. They might say "No smoking" and I would write that down. There may be times I ask you to say more to make sure I understand what you're thinking. For example, if someone looked at this sign and said it means, "You can't smoke near here," I would ask, "What do you mean by near?" Or I might just say, "Tell me more about that."

Following the instructions, the investigator started the audio-recorder, asked the participant to review one infographic and then said "Tell me what you think it means and I'll write it down," taking down the participant's responses verbatim. As the goal was to evaluate comprehension rather than recall, the participant had continued access to the infographic while they gave their interpretations of meaning. The process was repeated with the second infographic. At the end of the interview, participants were asked about their reactions to seeing their information.

Modification of the ISO 9186 method to verbal administration was necessary because it is less burdensome to low-literacy respondents and because the infographics contained much more information than the symbols for which the method was originally intended. The purpose of both the instructions and the note-taking was to encourage enough granularity from the participant's responses to adequately gauge comprehension. Direct questions such as, "How much air did you blow out in one second?" were only used if open-ended prompts failed to yield sufficiently detailed responses. The permissible direct questions, relating to both gist and verbatim comprehension, are shown in -Table 1 in the scoring rubric along with the scoring criteria. Two independent raters, who had not been present for the interview, were provided with the scoring rubric with the correct responses filled in, a copy of the participant's infographics from which the correct responses were drawn, and a transcript of the interview. In the event of a disagreement between raters, a third tie-breaking rater would be used. 
Today, you answered some questions about your asthma symptoms.

Here are your results.
JENNY'S LEVEL OF ASTHMA CONTROL

\section{Your asthma is not in control}

Your score is 2.5

You made good progress!

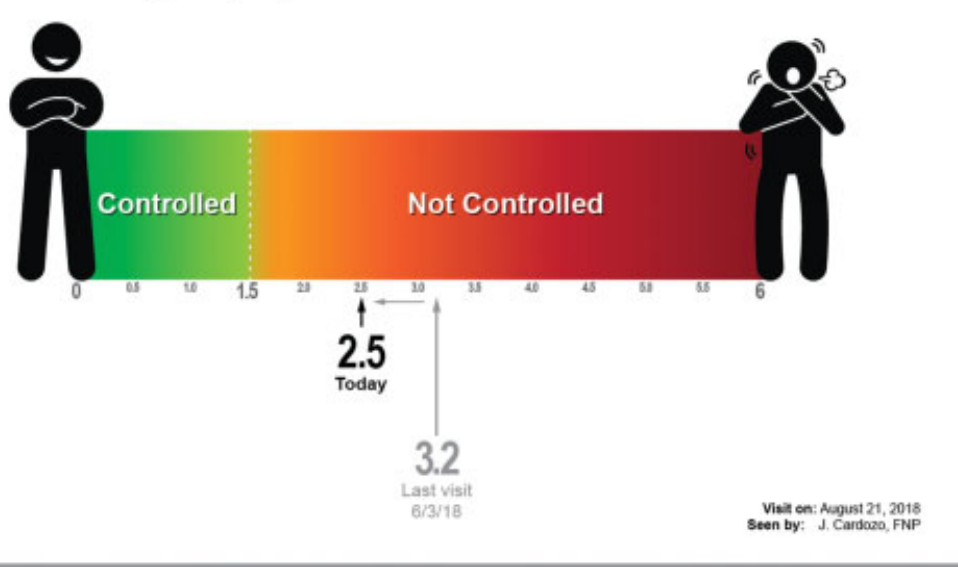

Fig. 3 Front cover (L) and inside (R) of pamphlet to show Asthma Control Questionnaire (ACQ) scores at two time points. Redundancy in imagery, colors, and interpretive statements reinforces meaning. CC BY 4.0 Adriana Arcia \& Nicole Spiegel-Gotsch for Columbia Nursing, https:// doi.org/10.7916/d8-w8hz-w605, p. 3.

\section{Results}

\section{Phase I, Iterative Participatory Design Sessions}

We conducted five iterative participatory design sessions (4 English, $n=18$; 1 Spanish, $n=3$ ) with 21 Hispanic (38\%) and non-Hispanic black (62\%) adults. As shown in - Table 2 , mean age was 50.2 (range $31-73$ ), $71 \%$ were female, $62 \%$ had a high school diploma or less, and $81 \%$ had uncontrolled asthma. Fewer than $30 \%$ had adequate health literacy, by NVS scores. By the conclusion of Phase I, participants expressed satisfaction with the final prototypes, shown in - Figs. 3 and 4, indicating that they were easy to understand and appealing. For example, in Session 5, one participant said, of the PFT infographic, "It's self-explanatory," and another commented, "I just... I like this. I like this a lot. A lot."

\section{Design Improvements}

The initial ACQ prototype design used a RRNL format that has consistently performed well in other studies with a variety of health-related variables. ${ }^{15,17-21}$ As expected, it was successful in our design sessions and thus we made only modest design improvements over the course of the sessions. Specifically, we deliberately introduced redundancies to the design because we realized that giving a viewer multiple meaning cues (e.g., text and color and illustrations) gives the viewer confidence that they have arrived at the correct conclusion about the data and also supports the needs of viewers with color blindness. Therefore, we added illustrations to anchor the endpoints of the number line and included interpretive statements (e.g., "Your asthma is not in control"). We also converted from a landscape page to a pamphlet format and created a version which includes the display of a previous score for comparison. For the latter, if the most recent score was controlled, we changed the interpretive statement to read "Great job - your asthma is in control!" If not, we included a second interpretive statement based on whether there was a clinically meaningful difference between the two scores: "It is about the same as at your last visit" for changes less than 0.5 units, "You made good progress!" for score reductions of 0.5 units or more, or "It has gotten worse since your last visit" for score increases of 0.5 units or more.

Unlike the ACQ prototype, the initial PFT prototype designs were wholly unsuccessful and thus underwent substantial changes to imagery, information hierarchy, and layout. Most importantly, we shifted our approach from that of an information display (i.e., presenting information with sufficient contextual cues to support interpretation) to a visual explanation ${ }^{52}$ which leads the viewer through the information in a systematic, narrative fashion, scaffolding the necessary concepts to make them more accessible. We used images of soda bottles to help convert a metric that is not intuitive for many Americans (liters) into familiar terms. This approach proved to be very useful to the participants generally but was especially memorable for one Session 4 participant in particular:

Participant: "Your image of the two-liter bottles, if I wake up in the morning from now on and I'm having problems breathing before I take my medicine-I'm going to think about the bottle."

$$
\text { Interviewer: "You are?" }
$$

Participant: "Yeah, that's going to pop in my head from now on. So, the image is going to be with me forever now." 

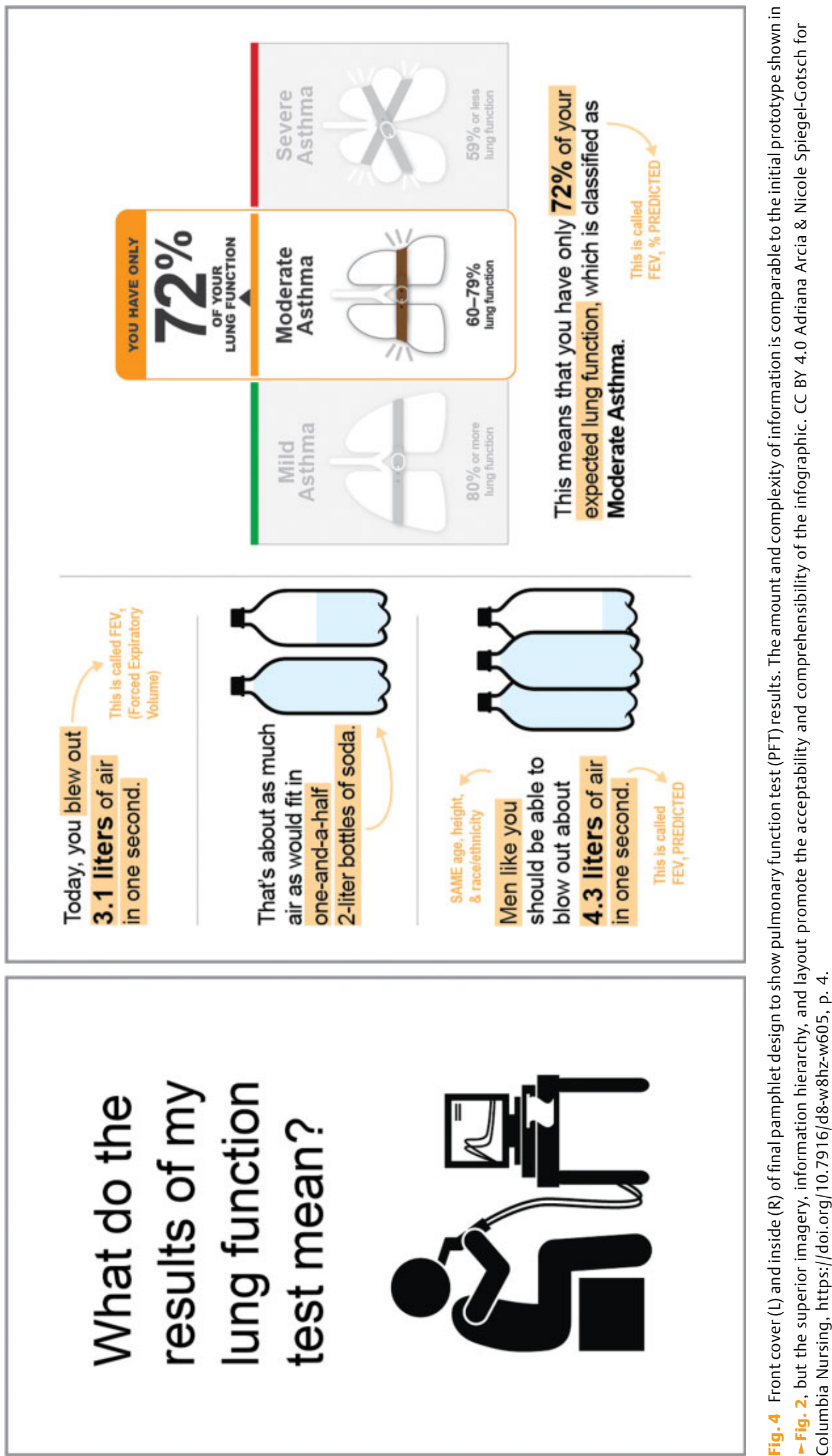
Table 1 Scoring rubric for Phase II individual comprehension assessment interviews

\begin{tabular}{|c|c|c|c|}
\hline Asthma Control Questionnaire pamphlet & Correct response & Correct & Incorrect \\
\hline Is your asthma controlled or not? & $\begin{array}{l}\circ \text { Yes } \\
\circ \text { No }\end{array}$ & $\square$ & $\square$ \\
\hline What is your asthma control score? & -__-_- & $\square$ & $\square$ \\
\hline Lung function test pamphlet & Correct response & Correct & Incorrect \\
\hline Is your asthma mild, moderate, or severe? & $\begin{array}{l}\text { - Mild } \\
\text { - Moderate } \\
\text { - Severe }\end{array}$ & $\square$ & $\square$ \\
\hline How much air did you blow out in 1 second? & 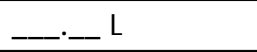 & $\square$ & $\square$ \\
\hline How much air is expected for patients like you? & _-_._L L & $\square$ & $\square$ \\
\hline What percentage of your lung function do you have? & ___ $\%$ & $\square$ & $\square$ \\
\hline \multicolumn{4}{|c|}{$\begin{array}{l}\text { Scoring Criteria (select one) } \\
\text { - Less than minimum comprehension: one or both gist (bolded) items is incorrect; } 0 \text { to } 4 \text { verbatim (nonbolded) items is correct } \\
\text { - Minimum comprehension: both gist (bolded) items are correct but no verbatim (non-bolded) items are correct } \\
\text { - More than minimum comprehension: both gist (bolded) items are correct and one or more verbatim (nonbolded) items is } \\
\text { correct. } \\
\text { - Complete comprehension: all items are correct. }\end{array}$} \\
\hline
\end{tabular}

For both infographics, the stoplight colors helped to convey value judgments and the imagery reflected the subjective experience of asthma. The images of the belted lungs in the PFT infographic were particularly well-liked for their ability to convey asthma severity. Reactions to them in Session 5 were very favorable:

Interviewer: So, what about the image of the lungs? Does that ...?

Participant 1: That's all it.

Participant 2: That comes across perfect.

Participant 3: That makes it crystal-clear.

Participant 4: All us asthmatics know how this feels.

Participant 1: You couldn't have put this better.

We also added three bulleted lines labeled "Plan for you" to the back cover (not shown) as a space for the clinician to fill in care plan action points. This feature was included in response to participants' assertion that understanding their asthma control status was not enough; they wanted to know what they should do about it.

Participants liked the idea of having a printed copy of their infographic to take home because they could easily share the information with loved ones:

Participant 1: They can understand it. [For] a person that doesn't have asthma and don't [sic] know what you go through, this is like, awesome. Two belts?!

Some mentioned the value of being able to easily make sense of the information at a later date:
Participant 3: That works even three months down the road, when you've got papers all over the place and you're just looking. Half the time, if you've just got all those discharge papers with a lot of mumbo-jumbo stuff on it, nine times out of ten, it's going to get chucked before you even realize what you did. That you'll keep.

\section{Phase II, Individual Comprehension Assessment Interviews}

We conducted comprehension assessment interviews in English with 10 adults (2 Hispanic, 7 non-Hispanic black, 1 refused). Mean age was 42.2 years (range 25-59), 7 were female, 4 had a high school diploma or less, and 6 had uncontrolled asthma (see - Table 2). According to NVS scores, 6 participants had adequate health literacy; the remaining 4 were classified has having a possibility of limited literacy.

All 10 participants demonstrated complete gist and verbatim comprehension for both infographics; there were no disagreements between raters. In a few cases, participants' results were better or worse than what they had said they expected them to be, but unexpectedness seemed not to have hindered comprehension given the complete comprehension.

\section{Participant Reactions to Their Tailored Infographics}

Participants reacted very favorably to receiving their information via infographics and expressed intentions to engage in self-management behaviors such as medication adherence, avoiding triggers, smoking cessation, stress reduction, weight loss, and reviewing their care plan with their clinician:

“I need to take my medicine more." (Interviewee \#9)

"Well, I'm going to continue to watch my weight. I'm going to take - I'm going to continue to try to stop smoking, the 
Table 2 Participant characteristics

\begin{tabular}{|c|c|c|c|c|}
\hline & \multicolumn{2}{|c|}{$\begin{array}{l}\text { Phase I participatory design } \\
\text { sessions }\end{array}$} & \multicolumn{2}{|c|}{$\begin{array}{l}\text { Phase II comprehension } \\
\text { interviews }\end{array}$} \\
\hline & $n$ & (\%) & $n$ & $(\%)$ \\
\hline \multicolumn{5}{|l|}{ Gender } \\
\hline Male & 6 & (29) & 3 & $(30)$ \\
\hline Female & 15 & (71) & 7 & $(70)$ \\
\hline \multicolumn{5}{|l|}{ Language } \\
\hline English & 18 & (86) & 10 & $(100)$ \\
\hline Spanish & 3 & (14) & 0 & $(0)$ \\
\hline \multicolumn{5}{|l|}{ Location } \\
\hline New York City & 11 & (52) & 3 & $(30)$ \\
\hline Philadelphia & 10 & $(48)$ & 7 & $(70)$ \\
\hline \multicolumn{5}{|l|}{ Race/Ethnicity } \\
\hline Hispanic & 8 & (38) & 2 & $(20)$ \\
\hline Non-Hispanic black & 13 & (62) & 7 & $(70)$ \\
\hline Refused & 0 & $(0)$ & 1 & $(10)$ \\
\hline \multicolumn{5}{|l|}{ Education } \\
\hline Some high school & 5 & (24) & 1 & $(10)$ \\
\hline High school diploma & 8 & (38) & 3 & $(30)$ \\
\hline Some college & 7 & (33) & 2 & $(20)$ \\
\hline Associate's & 0 & $(0)$ & 1 & $(10)$ \\
\hline Bachelor's & 1 & (5) & 2 & $(20)$ \\
\hline Education missing & 0 & $(0)$ & 1 & $(10)$ \\
\hline \multicolumn{5}{|l|}{ Health Insurance } \\
\hline Medicaid & 10 & $(48)$ & 10 & $(100)$ \\
\hline Military/VA & 2 & $(10)$ & 0 & $(0)$ \\
\hline Commercial & 5 & $(24)$ & 0 & $(0)$ \\
\hline Missing & 4 & (19) & 0 & $(0)$ \\
\hline \multicolumn{5}{|l|}{ Asthma control } \\
\hline Controlled & 4 & (19) & 4 & $(40)$ \\
\hline Uncontrolled & 17 & $(81)$ & 6 & $(60)$ \\
\hline \multicolumn{5}{|l|}{ Pulmonary function test results } \\
\hline Mild asthma & - & - & 4 & $(40)$ \\
\hline Moderate asthma & - & - & 6 & $(60)$ \\
\hline Severe asthma & - & - & 0 & $(0)$ \\
\hline \multicolumn{5}{|l|}{ Health literacy } \\
\hline High likelihood of limited literacy & 6 & (29) & 0 & $(0)$ \\
\hline Possibility of limited literacy & 9 & (43) & 4 & $(40)$ \\
\hline \multirow[t]{2}{*}{ Adequate literacy } & 6 & (29) & 6 & $(60)$ \\
\hline & Mean & Range & Mean & Range \\
\hline Mean income per person in household per year & $9,789^{a}$ & $2,460-18,000$ & $9,240^{\mathrm{b}}$ & $0-33,996$ \\
\hline Mean age & $50.2^{\mathrm{a}}$ & $31-73$ & 42.2 & $25-59$ \\
\hline
\end{tabular}

Abbreviation: VA, Veterans Affairs.

${ }^{\mathrm{a}} n=20$.

$b_{n}=8$. 
patch is too strong for me, I've tried that in the past. The gum is horrible, it really tastes bad, so I got to have to just stop on my own. So, I'm going to just put my best foot forward and try to stop." (Interviewee \#10)

Given the option of being given their information verbally, via text, or with an infographic, all wanted the infographic every time they had an ACQ score or PFT result, with a few indicating they would also want the information verbally:

"But you know like in - like these pictures and stuff. Like, that speaks a lot more for a lot of people." (Interviewee \#10)

Interview participants had no further suggestions to improve the infographic designs.

\section{Discussion}

\section{Visualization Innovations}

This study provides preliminary evidence that tailored infographics can support comprehension of asthma control status and promote self-management intentions among adults with persistent asthma. This is an important contribution because although there are a variety of asthmarelated information visualizations documented in the literature, none provided sufficient guidance for displaying asthma control scores or PFT results. As predicted by the Health Belief Model, ${ }^{14}$ participants regarded the infographics as cues to taking preventive health actions such as improved medication adherence and smoking cessation.

Based on prior research, we felt confident that the RRNL format could be adapted successfully to display ACQ scores. In this study, we make a modest contribution by showing how redundancies in text, color, and imagery can be used to underscore meaning and how two data points can be effectively displayed on one number line. A simple algorithm is all that is needed to generate interpretive statements that accurately characterize the recent trend in a patient's ACQ score. Interpretive statements celebrating a clinically meaningful improvement despite a lack of asthma control may help keep patients with asthma from becoming discouraged by their results. ${ }^{53}$ This enhanced RRNL format can easily be adapted to display other measures of asthma control such as the $\mathrm{ACT}^{45}$ and the Asthma Therapy Assessment Questionnaire. ${ }^{54}$

Our design for a tailored PFT infographic represents a substantial innovation because it has a very high level of information complexity compared with tailored patientfacing visualizations currently documented in the literature. $^{19-22}$ Success required demystifying unfamiliar terminology, clarifying that reference criteria varied according to personal characteristics, and explaining the subtle distinctions between three different results $\left(\mathrm{FEV}_{1}, \mathrm{FEV}_{1}\right.$ predicted, and $\mathrm{FEV}_{1} \%$ predicted) on two different metrics (liters and percentages). Our use of the soda bottle imagery capitalized on the only liter referent likely to be familiar to most Americans. Showing bottles for both the amount the patient blew out and for the expected amount allowed us to visually represent the part-to-whole relationship of unobstructed to total lung volume. The images of the belted lungs, inspired by the Dalhousie Dyspnea Scale, ${ }^{40}$ were compelling because they accurately reflected participants' subjective experience of asthma exacerbation.

\section{Patients' Information Needs}

Our findings highlight some needs that patients have with respect to acquiring and sharing/storing information. Our participants made it clear that awareness of their asthma control status was only useful when accompanied by information about appropriate self-management actions to achieve or maintain asthma control (i.e., "Plan for You"). This finding is similar to prior studies of patients' responses to receiving test results via portal, ${ }^{55}$ and is consistent with the ethos behind the use of Infobuttons for linking out to additional information about a given topic. ${ }^{56}$ It is also in line with current best practices for sharing clinical data with patients. $^{53,57}$ Participants also reminded us of the importance of easily sharing their health information with loved ones. In this use case, participants appreciated having a printed infographic to show to a family member or friend or to save for future reference. In other instances, however, digital tools, such as health apps and patient portals, will be the preferable media and thus must help patients strike a balance between data security and easy sharing.

\section{Informatics Requirements for Implementation}

Infographics can be programmed into electronic health records and/or standalone applications to allow for instant tailoring at the point of care. Ideally, ACQ scores and PFT results are captured, stored, and extracted electronically. However, manual entry also may be used to input the data necessary for tailoring the infographics. Clinicians can use pick lists, dropdown menus, or free-text entry to customize interpretive statements and the care plan summary. Alternatively, care plan action items can be handwritten on the back of the already-tailored and printed infographic pamphlet as part of a shared decision-making conversation with the patient. The ACQ design is flexible in that blank versions can be preprinted on tear sheets and hand-tailored in pen or laminated and marked up with a dry erase marker. These types of adaptations are useful for low-resource settings where computerized tailoring and/or color printing are not readily available. The complexity of the PFT infographic, however, requires automated tailoring using a system that can covert patient data into a completed infographic. ${ }^{31}$ Patients who are comfortable using portals and apps may prefer to receive their tailored infographics digitally through those means. Tools such as the Substitutable Medical Applications and Reusable Technologies (SMART) and the Fast Health Interoperability Resource (FHIR) Health Level Seven standard make it possible to create applications that interface with electronic health records. ${ }^{58}$

\section{Limitations}

Various limitations were evident in this study. We had few Spanish speakers in Phase I and were unsuccessful recruiting any for Phase II; additional work may be needed to ensure the acceptability of the translated text. Also, our participants in 
Phase II had slightly higher literacy and education than those in Phase I, which could have influenced the favorability of our results. Asking participants what they expected their results to be may have primed them in a way that improved the likelihood of correct response. We were willing to accept this limitation because we felt it important to explore whether the unexpectedness of a result might forestall comprehension, as has been documented in other studies. ${ }^{49}$ Our homogenous results and small sample size (due to funding constraints) prevented a thorough exploration of this topic; larger studies are needed and therefore we have characterized our results as preliminary.

Social desirability bias can affect design studies, particularly if there is a perceived power differential between the study team and the participants. ${ }^{59}$ We believe that the findings most vulnerable to this bias are those related to behavioral intentions and we acknowledge this limitation. A future study is warranted measuring actual performance of the desired behaviors. We think it unlikely that social desirability had a substantial impact on the design process, however, largely because participants appeared uninhibited in their expressions of distaste for designs they did not like, both verbally (e.g., "I don't like the image," "very confusing") and in their body language (e.g., grimacing, pushing the paper away).

\section{Future Work}

The infographics we have designed are intended to meet the specific needs of low-literacy audiences. However, all humans have limited working memory for acquiring new information, irrespective of literacy level. ${ }^{13}$ Therefore, materials that introduce new information in a way that minimizes cognitive load should theoretically ease learning for everyone. We expect that our designs will be appealing to and comprehended by a broad range of patients but verification is needed with further empirical testing. In addition to testing in other populations, next steps include research on the effect of tailored asthma infographics on medication adherence and asthma control. If infographics are found to be efficacious, implementation toolkits could be promoted through professional organizations such as the Patient and Family Education Committee of the American Thoracic Society or the American Lung Association.

\section{Conclusion}

Tailored infographics are a promising approach to making asthma control status easily comprehensible for adults with persistent asthma. Integration with electronic health records will enable instant tailoring at the point of care so that clinicians have easy access to a communication tool that can support a conversation about medication adherence and other asthma self-management behaviors.

\section{Clinical Relevance Statement}

Low health literacy is a barrier to comprehension of asthma control status and may hinder engagement in self-management behaviors. This study highlights how tailored infographics can be used to support comprehension of asthma control and motivate intentions to engage in self-management behaviors. Informatics-based tools will be necessary to automate tailoring of infographics in service of improved patient-provider communication.

\section{Multiple Choice Questions}

1. How did the authors assess comprehension of tailored asthma control infographics among adults with persistent asthma?

a. By saying, "write down what you think it means."

b. By saying, "tell me what you think it means and I'll write it down."

c. By asking, "what is your reaction to seeing this information?"

d. By collecting responses to a survey using 5-point Likert response options.

Correct Answer: The correct answer is option b, by saying, "tell me what you think it means and I'll write it down." The authors used a modified International Organization Standardization (ISO) 9186 method to assess comprehension by saying, "tell me what you think it means and I'll write it down," as opposed to the original comprehension testing method, which is to direct participants to "write down what you think it means." Verbal assessment is less burdensome than written assessment for low-literacy respondents and encourages the length and granularity of response necessary to assess comprehension of multiple pieces of information.

2. What did participants in the study express after exposure to infographics tailored with data about their own level of asthma control?

a. Intention to attend fewer scheduled clinician visits.

b. Desire to receive this information through a mobile application.

c. Intention to engage in self-management behaviors.

d. Increased confusion about their asthma control status.

Correct Answer: The correct answer is: option c, intention to engage in self-management behaviors. In this study, participants reacted favorably to receiving the information displayed in infographics and in a pamphlet form. Participants also expressed intentions to engage in self-management behaviors such as medication adherence, smoking cessation, weight loss, and review of their care plan with their clinician.

\section{Protection of Human and Animal Subjects}

The study was performed in compliance with the World Medical Association Declaration of Helsinki on Ethical Principles for Medical Research Involving Human Subjects, and was reviewed by the Columbia University Medical Center Institutional Review Board.

\section{Funding}

This work was supported by an intramural grant from Columbia University School of Nursing. Dr. Lor and Ms. 
Mangal were supported by T32 NR007969 Reducing Health Disparities through Informatics (RHeaDI).

\section{Conflict of Interest}

M.G. serves as an advisor to Astra Zeneca and on the Advisory Board to Teva. The other authors report no conflicts of interest in the research. M.G. reports personal fees from AstraZeneca, personal fees from Teva, outside the submitted work.

\section{Acknowledgments}

We are grateful to Nicole Spiegel-Gotsch for her invaluable graphic design contributions; to Jeanette Kreuze, Glynis Joynes, and Annie Chung for help with participant recruitment; to Niurka Suero-Tejeda for assistance with data collection and analysis; to Stephen Ferrara and Diana Hernandez for access to equipment; and to Bruce Levin, Patti Weir, and Natalia Villegas-Rodriguez for monitoring the safety of the study.

\section{References}

1 National Asthma Education and Prevention Program. Expert Panel Report 3 (EPR-3): Guidelines for the Diagnosis and Management of Asthma-Summary Report 2007. J Allergy Clin Immunol 2007;120 (5, Suppl):S94-S138

2 Murphy KR, Meltzer EO, Blaiss MS, Nathan RA, Stoloff SW, Doherty DE. Asthma management and control in the United States: results of the 2009 Asthma Insight and Management survey. Allergy Asthma Proc 2012;33(01):54-64

3 Akinbami LJ, Moorman JE, Bailey C, et al. Trends in asthma prevalence, health care use, and mortality in the United States, 2001-2010. NCHS Data Brief 2012;(94):1-8

4 Sentell T, Braun KL. Low health literacy, limited English proficiency, and health status in Asians, Latinos, and other racial/ethnic groups in California. J Health Commun 2012;17(Suppl 3):82-99

5 Apter AJ, Wan F, Reisine S, et al. The association of health literacy with adherence and outcomes in moderate-severe asthma.J Allergy Clin Immunol 2013;132(02):321-327

6 Garg VK, Bidani R, Rich EP, Hershey E, Hershey CO. Asthma patients' knowledge, perception, and adherence to the asthma guidelines. J Asthma 2005;42(08):633-638

7 Thai AL, George M. The effects of health literacy on asthma selfmanagement. J Asthma Allergy Educ 2010;1(02):50-55

8 Apter AJ, Cheng J, Small D, et al. Asthma numeracy skill and health literacy. J Asthma 2006;43(09):705-710

9 Harrington KF, Zhang B, Magruder T, Bailey WC, Gerald LB. The impact of parent's health literacy on pediatric asthma outcomes. Pediatr Allergy Immunol Pulmonol 2015;28(01):20-26

10 Valerio MA, Peterson EL, Wittich AR, Joseph CLM. Examining health literacy among urban African-American adolescents with asthma. J Asthma 2016;53(10):1041-1047

11 Wood MR, Price JH, Dake JA, Telljohann SK, Khuder SA. African American parents'/guardians' health literacy and self-efficacy and their child's level of asthma control. J Pediatr Nurs 2010;25(05): 418-427

12 Paasche-Orlow MK, Riekert KA, Bilderback A, et al. Tailored education may reduce health literacy disparities in asthma selfmanagement. Am J Respir Crit Care Med 2005;172(08):980-986

13 Sweller J, van Merriënboer JJG, Paas F. Cognitive architecture and instructional design: 20 years later. Educ Psychol Rev 2019. Doi: 10.1007/s10648-019-09465-5

14 Janz NK, Becker MH. The Health Belief Model: a decade later. Health Educ Q 1984;11(01):1-47
15 Zikmund-Fisher BJ, Scherer AM, Witteman HO, et al. Graphics help patients distinguish between urgent and non-urgent deviations in laboratory test results. J Am Med Inform Assoc 2017;24(03):520-528

16 Nystrom DT, Singh H, Baldwin J, Sittig DF, Giardina TD. Methods for patient-centered interface design of test result display in online portals. EGEMS (Wash DC) 2018;6(01):15

17 Brewer NT, Gilkey MB, Lillie SE, Hesse BW, Sheridan SL. Tables or bar graphs? Presenting test results in electronic medical records. Med Decis Making 2012;32(04):545-553

18 Solomon J, Scherer AM, Exe NL, Witteman HO, Fagerlin A, Zikmund-Fisher BJ. Is this good or bad? Redesigning visual displays of medical test results in patient portals to provide context and meaning. In: Proceedings of the $2016 \mathrm{CHI}$ Conference Extended Abstracts on Human Factors in Computing Systems - CHI EA '16. New York, New York, USA: ACM Press; 2016: 2314-2320

19 Scherer AM, Witteman HO, Solomon J, Exe NL, Fagerlin A, Zikmund-Fisher BJ. Improving the understanding of test results by substituting (not adding) goal ranges: web-based between-subjects experiment. J Med Internet Res 2018;20(10):e11027

20 Tao D, Yuan J, Qu X. Presenting self-monitoring test results for consumers: the effects of graphical formats and age. J Am Med Inform Assoc 2018;25(08):1036-1046

21 Arcia A, Suero-Tejeda N, Bales ME, et al. Sometimes more is more: iterative participatory design of infographics for engagement of community members with varying levels of health literacy. J Am Med Inform Assoc 2016;23(01):174-183

22 McDowell M, Gigerenzer G, Wegwarth O, Rebitschek FG. Effect of tabular and icon fact box formats on comprehension of benefits and harms of prostate cancer screening: a randomized trial. Med Decis Making 2019;39(01):41-56

23 Ancker JS, Senathirajah Y, Kukafka R, Starren JB. Design features of graphs in health risk communication: a systematic review. J Am Med Inform Assoc 2006;13(06):608-618

24 Garcia-Retamero R, Okan Y, Cokely ET. Using visual aids to improve communication of risks about health: a review. ScientificWorldJournal 2012;2012:562637

25 Katz MG, Kripalani S, Weiss BD. Use of pictorial aids in medication instructions: a review of the literature. Am J Health Syst Pharm 2006;63(23):2391-2397

26 Houts PS, Doak CC, Doak LG, Loscalzo MJ. The role of pictures in improving health communication: a review of research on attention, comprehension, recall, and adherence. Patient Educ Couns 2006;61(02):173-190

27 Morrow DG, Hier CM, Menard WE, Leirer VO. Icons improve older and younger adults' comprehension of medication information. J Gerontol B Psychol Sci Soc Sci 1998;53(04):240-254

28 Yin HS, Parker RM, Sanders LM, et al. Pictograms, units and dosing tools, and parent medication errors: a randomized study. Pediatrics 2017;140(01):e20163237

29 Barros IM, Alcântara TS, Mesquita AR, et al. Understanding of pictograms from the United States Pharmacopeia Dispensing Information (USP-DI) among elderly Brazilians. Patient Prefer Adherence 2014;8:1493-1501

30 Arcia A, Suero-Tejeda N, Spiegel-Gotsch N, Luchsinger JA, Mittelman M, Bakken S. Helping Hispanic family caregivers of persons with dementia "get the picture" about health status through tailored infographics. Gerontologist 2019:pii:gnz085

31 Arcia A, Velez M, Bakken S. Style Guide: an interdisciplinary communication tool to support the process of generating tailored infographics from electronic health data using EnTICE ${ }^{3}$. EGEMS (Wash DC) 2015;3(01):1120

32 Yin HS, Gupta RS, Tomopoulos S, et al. A low-literacy asthma action plan to improve provider asthma counseling: a randomized study. Pediatrics 2016;137(01):1-11

33 Kristiansen J, Hetutu E, Manukia M, Jelleyman T. An evaluation of a pictorial asthma medication plan for Pacific children. $\mathrm{N} Z$ Z Med J 2012;125(1354):42-50 
34 Farber HJ, Smith-Wong K, Nichols L, Langham B. Patients prefer simple, visual asthma self-management plan forms. Perm J 2001; 5:35-37

35 Lefco M, Gise J, Lesnick B, Arriaga RI. Even when icons are not worth a thousand words they are helpful in designing asthma mHealth tools. In: Bernhaupt R, Dalvi G, Joshi A, Balkrishan DK, O'Neill J, Winckler M, eds. Human-Computer Interaction INTERACT 2017. Vol. 10515. Lecture Notes in Computer Science. Cham, Switzerland: Springer International Publishing; 2017: 23-33

36 Roberts NJ, Evans G, Blenkhorn P, Partridge MR. Development of an electronic pictorial asthma action plan and its use in primary care. Patient Educ Couns 2010;80(01):141-146

37 Smythe KC, Carla G, Spinillo CMAS. Redesign of packaging and labeling of drug based on user-centered design information. Blucher Design Proc 2014;1(02):298-312

38 Kools M, van de Wiel MWJ, Ruiter RAC, Kok G. Pictures and text in instructions for medical devices: effects on recall and actual performance. Patient Educ Couns 2006;64(1-3):104-111

39 Fritz G, Spirito A, Yeung A, Klein R, Freedman E. A pictorial visual analog scale for rating severity of childhood asthma episodes. J Asthma 1994;31(06):473-478

40 Pianosi P, Smith CP, Almudevar A, McGrath PJ. Dalhousie Dyspnea Scales: Pictorial scales to measure dyspnea during induced bronchoconstriction. Pediatr Pulmonol 2006;41(12):1182-1187

41 Turner-Bowker DM, Saris-Baglama RN, Derosa MA, Paulsen CA, Bransfield CP. Using qualitative research to inform the development of a comprehensive outcomes assessment for asthma. Patient 2009; 2(01):269-282

42 Rudin RS, Fanta $\mathrm{CH}$, Predmore $\mathrm{Z}$, et al. Core components for a clinically integrated mHealth app for asthma symptom monitoring. Appl Clin Inform 2017;8(04):1031-1043

43 Schneider T, Baum L, Amy A, Marisa C. I have most of my asthma under control and I know how my asthma acts: users' perceptions of asthma self-management mobile app tailored for adolescents. Health Informatics J 2019. Doi: 10.1177/1460458218824734

44 Tulloch J, Irwin D, Pascuet E, Vaillancourt R. Evaluation, modification and validation of a set of asthma illustrations in children with chronic asthma in the emergency department. Can Respir J 2012; 19(01):26-31

45 Nathan RA, Sorkness CA, Kosinski M, et al. Development of the Asthma Control Test: a survey for assessing asthma control. J Allergy Clin Immunol 2004;113(01):59-65
46 Juniper EF, Bousquet J, Abetz L, Bateman ED; GOAL Committee. Identifying 'well-controlled' and 'not well-controlled' asthma using the Asthma Control Questionnaire. Respir Med 2006;100 (04):616-621

47 Weiss BD, Mays MZ, Martz W, et al. Quick assessment of literacy in primary care: the Newest Vital Sign. Ann Fam Med 2005;3(06): 514-522

48 Arcia A, George M. Reference range number line format preferred by adults for display of asthma control status. J Asthma 2019. Doi: 10.1080/02770903.2019.1590597

49 Renner B. Biased reasoning: adaptive responses to health risk feedback. Pers Soc Psychol Bull 2004;30(03):384-396

50 ISO. ISO 9186-1:2014 Graphical Symbols-Test Methods-Part 1: Method for Testing Comprehensibility. Geneva: International Organization for Standardization; 2014

51 Brantley KA, Wogalter MS. Oral and written symbol comprehension testing: the benefit of cognitive interview probing. In: Proceedings of the Human Factors and Ergonomics Society Annual Meeting. Los Angeles, CA: Sage Publications; 1999:1060-1064

52 Tufte ER, Robins D. Visual Explanations: Images and Quantities, Evidence and Narrative. Cheshire, CT: Graphics Press; 1997

53 Witteman HO, Zikmund-Fisher BJ. Communicating laboratory results to patients and families. Clin Chem Lab Med 2019;57 (03):359-364

54 Vollmer WM, Markson LE, O'Connor E, et al. Association of asthma control with health care utilization and quality of life. Am J Respir Crit Care Med 1999;160(5 Pt 1):1647-1652

55 Giardina TD, Baldwin J, Nystrom DT, Sittig DF, Singh H. Patient perceptions of receiving test results via online portals: a mixedmethods study. J Am Med Inform Assoc 2018;25(04):440-446

56 Long J, Hulse NC, Tao C. Infobutton usage in patient portal MyHealth. AMIA Jt Summits Transl Sci Proc 2015;2015:112-116

57 Zikmund-Fisher BJ. Helping people know whether measurements have good or bad implications: increasing the evaluability of health and science data communications. Policy Insights Behav Brain Sci 2019;6(01):29-37

58 Mandel JC, Kreda DA, Mandl KD, Kohane IS, Ramoni RB. SMART on FHIR: a standards-based, interoperable apps platform for electronic health records. J Am Med Inform Assoc 2016;23(05):899-908

59 Dell N, Vaidyanathan V, Medhi I, Cutrell E, Thies W. "Yours is better!" Participant response bias in $\mathrm{HCl}$. In: Proceedings of the 2012 ACM Annual Conference on Human Factors in Computing Systems - CHI '12. New York, NY: ACM Press; 2012:1321 